\title{
Research Square \\ Control Study between CT Signs and Pathological Subtypes and Differentiation Degree in Lung Adenocarcinoma
}

\section{Lizhen Duan}

The Affiliated Huai'an No.1 People's hospital of Nanjing Medical University

\section{Wenli Shan}

The Affiliated Huai'an No.1 People's Hospital of Nanjing Medical University

\section{Genji Bo}

The Affiliated Huai'an No.1 People's Hospital of Nanjing Medical University

\section{Guangming Lu}

The Affiliated Jinling Hospital, Medical School of Nanjing University

\section{Lili Guo ( $\square$ guolili163@163.com )}

The Affiliated Huai'an No.1 People's Hospital of Nanjing Medical University https://orcid.org/00000002-4034-6968

\section{Research article}

Keywords: Lung adenocarcinoma, Computed Tomography, sign, pathology, differentiation

Posted Date: November 18th, 2019

DOl: https://doi.org/10.21203/rs.2.17418/v1

License: (c) (i) This work is licensed under a Creative Commons Attribution 4.0 International License. Read Full License 


\section{Abstract}

Background: To study the relationship between CT signs and pathological subtypes and differentiation degree in lung adenocarcinoma.

Methods: We retrospectively reviewed 394 cases' CT images of lung adenocarcinoma and compared the diversity of images among PIL, MIA and IAC, as well as differentiation degrees of IAC by Kruskal-Wall test and $\mathrm{X} 2$ test.

Results: There was no statistical difference of CT sign between PIL and MIA (Pख0.05). There are statistical differences among size and density of PIL, MIA and IAC (P区0.01); the incidences of pleura traction sign, spicule sign, lobulation sign, tumor vascular sign, bronchial cut-off sign, air bronchogram sign and cavity sign in IAC were higher than the other two groups (P凶0.05); there was no statistical difference of vacuole sign among PIL, MIA and IAC (Pख0.05). There are statistical differences among size and density of three differentiated subgroups (Pख0.01); the incidences of pleura traction sign, spicule sign, tumor vascular sign, bronchial cut-off sign and cavity sign in poorly differentiated subgroup were highest (P囚0.01); the incidence of air bronchogram sign in highly differentiated subgroup was higher than moderately and poorly differentiated subgroup while incidence of lobulation sign was the lowest in three subgroups above $(\mathrm{P} \otimes 0.05)$; there was no statistical difference of vacuole sign among three differentiated subgroups $(\mathrm{P} \otimes 0.05)$.

Conclusions: CT signs of lung adenocarcinoma are closely related to pathological subtypes and differentiation degrees $₫$ which would have great value to help predict tumor types and make treatment plans in clinical.

\section{Backgound}

Lung cancer is the most frequent cause of major cancer incidence and mortality worldwide ${ }^{[1-2]}$. Up to now, the squamous cell carcinoma (SCC) was surpassed by lung adenocarcinoma as the highest incidence of lung cancer ${ }^{[3]}$, and adenocarcinoma is the most common histologic subtype of lung cancer in most countries, accounting for almost half of all lung cancers, which threatened people's health and quality of life seriously ${ }^{[4]}$. The lung cancer classification system launched by WHO accepted the pathological classification method in 2015, which co-sponsored by the International Association for the Study of Lung Cancer, American Thoracic Society and European Respiratory Society in $2011^{[5]}$. And lung adenocarcinomas are classified into atypical adenomatous hyperplasia (AAH), adenocarcinoma in situ (AIS), minimally invasive adenocarcinoma (MIA) and invasive adenocarcinoma (IAC) with adherent growth. Among them, AAH and AIS belong to the same pre-invasive lesions (PIL). Initial data studies using new classification methods in early resected adenocarcinoma indicated significant prognostic differences between histological subtypes ${ }^{[6]}$. Therefore, the early identification of histopathological subtypes of lung adenocarcinoma had profound significance for the presurgical diagnosis and treatment of early stage lung cancer. 
At present, the diagnosis of pathological subtypes of lung adenocarcinoma mainly depended on invasive pathological examination, such as percutaneous puncture, endoscopic biopsy and surgery ${ }^{[7]}$. Then, these methods can cause different degrees of damage to patients. Therefore, finding a safe, non-invasive and low-risk inspection method is an urgent clinical problem. Based on the data of the histopathologic subtypes and the clinical patterns/syndromes of Chinese medicine of 60 cases of primary peripheral lung cancer at the middle and later stages, the pathological subtypes of primary peripheral lung cancer were considered to be intrinsically related to patterns/syndromes of Chinese medicine and common herbal formulas ${ }^{[8]}$. There are many limitations in predicting different subtypes of adenocarcinoma from lung computed tomography (CT), such as the diverse radiomic descriptors and the difficulty of extracting effective radiomic descriptors from lung nodules. To overcome these challenges, a competing round-robin prediction model was elucidated by Chen, to predict the histological subtypes of lung adenocarcinoma. Based on 70 adenocarcinoma patients, the proposed model achieved an accuracy of $86.3 \%$ in predicting five histological subtypes of adenocarcinomas ${ }^{[9]}$. Then, 44 lung adenocarcinoma patients were studied by Cohen, which can differentiate AIS and MIA from IAC among subsolid lung nodules by computed tomography ${ }^{[10]}$. In addition, the segmentation techniques of computed tomographic three-dimensional (3D) indicated that computer-assisted 3D measurement of nodules at CT had good reproducibility and helped differentiate among subtypes of lung adenocarcinoma ${ }^{[11]}$. And other studies on pathological subtypes of lung adenocarcinoma were shown in ${ }^{[12-14]}$.

The paper is organized as follows. In the forthcoming section, CT findings of 394 patients with solitary lung adenocarcinoma were retrospectively analyzed. And the patients were divided into groups according to the WHO grading system. Subsequently, our researchers extract characteristic information from CT images, such as the size and density of lesions, pleural traction sign, lobulation sign, etc. Then, the characteristic signs of each group were collected and counted. The investigation attempts to show which CT signs are associated with pathological subtypes of lung adenocarcinoma and differentiation degree in lung adenocarcinoma, thereby assisting in guiding the clinical treatment and predict outcome. Later, the discussion and conclusion are given.

\section{Materials And Methods}

\section{Patient selection}

394 patients (226 males; 168 females; age range, 32-81 years; average age, $56.5 \pm 24.5$ years) with subsequent histologic confirmation of lung adenocarcinoma in Huai'an First People's Hospital were collected consecutively between October 2016 and September 2018. Inclusion criteria were histologically proven incident pulmonary lesion with complete chest CT imaging data. Exclusion criteria were received radiotherapy and chemotherapy. According to the pathological results, 394 patients were divided into PIL group, MIA group and IAC group, and IAC were divided into three subgroups: high differentiation, moderate differentiation and poor differentiation.

\section{CT imaging acquisition}


Imaging was performed on a 64-detector row dual source CT scanner (SIEMENS SOMATOM Definition Flash, Germany) with the following parameters: acquisition FOV 500 mm; beam pitch, 1.35 or 1.375; matrix 512x512; and gantry speed, 0.6 seconds per rotation, tube voltage $100 \mathrm{kV}$. The scanning areas ranged from the apex to the bottom of lung under the mode of Care Dose 4D. The current of tube were automatically adjusted. The section thickness was $1 \mathrm{~mm}$ for each transverse images. Then additional sagittal and coronal images were reconstructed.

\section{Analysis of imaging characteristics}

Two chest radiologists with 10 and 8 years of experience in thoracic imaging, respectively, who were blinded to the clinical and pathological data evaluated all images on both mediastinal (width, 350HU; level, $50 \mathrm{HU}$ ) and lung (width, $1200 \mathrm{HU}$; level, $-600 \mathrm{HU}$ ) windows. The characteristics of the lesion were observed as follows: 1) the margin of lesion (smooth or irregular); 2 ) the size (the average of the longest and shortest diameter of maximum area of the tumor on lung window image) of lesion; 3 ) the density of the lesion; 4) pleural traction sign; 5) tumor vascular sign; 6) spicule sign; 7) lobulation sign; 8) bronchial cut-off sign; 9) air bronchogram sign; 10) vacuole sign; 11) cavity sign. The evaluation and analysis of the images are carried out respectively. There will come to a consensus when dissimilarity of findings existed. The size of lesions in PIL group was $(1.44 \pm 0.92) \mathrm{cm}$, MIA group $(1.76 \pm 1.13) \mathrm{cm}$, IAC group $(3.52 \pm 2.41) \mathrm{cm}$. In this study, the size of lesions was divided into three grades: $\leq 1.5 \mathrm{~cm}, 1.5-3 \mathrm{~cm}$ and > $3 \mathrm{~cm}$, and their sizes were compared by the incidence of lesions in each group. The low density in noncalcified lesions demonstrates there were more ground-glass components in them, while the more solid components in lesions have the higher density. According to the density, the lesions were divided into three categories: pure ground-glass, mixed ground-glass and solid. The characteristics and the density of each group were compared and then CT signs of each group were deduced.

Typical case pictures are shown in Figure 1-5.

\section{Statistical analysis}

Statistical analysis was performed with IBM SPSS Statistics 22 Developer software packages. The size and density were analyzed by Kruskal-Wall test and signs were analyzed by chi-squared test. The corrected value and $P$-value are used when $\mathrm{I}<\mathrm{T}<5$ and $\mathrm{N}>40$; the $P$-value of Fisher Exact Probability Method when $\mathrm{T}<1$ or $\mathrm{N}<40$. In all test, $P$-value of $<0.05$ was considered as statistically significant.

\section{Results}

\section{Histopathological subtypes and CT signs}

The CT features of 394 patients in different groups of histopathological subtypes were extracted and analyzed. Then, the relationship between different pathological subtypes and these signs were expressed in Table 1. 
There was no statistical difference of CT sign between PIL and MIA ( $P \Downarrow 0.05)$. In IAC group, the incidence of lesions which size $\leq 1.5 \mathrm{~cm}$ and pure ground-glass were the lowest $(P<0.05)$. However, IAC group had the highest incidence of lesions which size $>3 \mathrm{~cm}$ and solid $(P<0.05)$. The lesions which size between 1.5 and $3 \mathrm{~cm}$ in MIA group had higher incidence than IAC group $(P<0.05)$. The incidence of pleural traction sign, spicule sign, lobulation sign, tumor vascular sign, bronchial cut-off sign, air bronchogram sign and cavity sign in IAC group were significantly higher than those in PIL group and MIA group $(P<0.05)$. These groups were not significantly associated with the incidence of margin irregularity and vacuole sign ( $P=0.309$ and $P=0.217$, respectively).

Table 1 Correlation of CT signs with histopathological subtypes of lung adenocarcinoma

A: Relationship of size and density with pathology

\begin{tabular}{|c|c|c|c|c|c|c|}
\hline pathology & size $\leq 1.5 \mathrm{~cm}$ & $\begin{array}{l}\text { Size } \\
1.5 \sim 3 \mathrm{~cm}\end{array}$ & $\begin{array}{l}\text { size } \mathbb{} \\
3 \mathrm{~cm}\end{array}$ & $\begin{array}{l}\text { Pure ground- } \\
\text { glass }\end{array}$ & $\begin{array}{l}\text { mixed ground- } \\
\text { glass }\end{array}$ & solid \\
\hline PIL & $28 * \#$ & 43 & $0 *$ & $57 *$ & 14 & $0 *$ \\
\hline MIA & $11^{\#}$ & $33^{\#}$ & $0^{\#}$ & $31^{\#}$ & 12 & $1^{\#}$ \\
\hline IAC & $8 * \#$ & $137^{\#}$ & $134^{*, \#}$ & $11 \%, \#$ & 49 & $\begin{array}{l}219 *, \\
\#\end{array}$ \\
\hline $\mathrm{H}$-value & 84.519 & & & 198.021 & & \\
\hline$P$-value & 0.000 & & & 0.001 & & \\
\hline
\end{tabular}

Note. Kruskal-Wall test

B: Relationship of margin irregularity, plural traction sign and spicule sign with pathology 
$\begin{array}{llllll}\text { Pathology } & \begin{array}{l}\text { Margin } \\ \text { irregularity }+\end{array} & \begin{array}{l}\text { Margin } \\ \text { irregularity }\end{array} & \begin{array}{l}\text { Pleural } \\ \text { traction sign }+\end{array} & \begin{array}{l}\text { Pleural } \\ \text { traction sign- }\end{array} & \begin{array}{l}\text { Spicule } \\ \text { sign }+\end{array}\end{array} \begin{aligned} & \text { Spicule } \\ & \text { sign }\end{aligned}$

\begin{tabular}{lllllll}
\hline PIL & 50 & 21 & $22^{*}$ & 49 & $5 *$ & 66 \\
\hline MIA & 32 & 12 & $17^{\#}$ & 27 & $4^{\#}$ & 40 \\
\hline IAC & 218 & 61 & $186^{*}, \#$ & 93 & $163^{*}, \#$ & 116 \\
\hline 2-value & 2.351 & & 36.315 & & 98.014 & \\
\hline$P$-value & 0.309 & & 0.000 & & 0.000 &
\end{tabular}

C: Relationship of lobulation sign, tumor vascular sign and bronchial cut-off sign with pathology

\begin{tabular}{lllllll} 
Pathology & $\begin{array}{l}\text { Lobulation } \\
\text { sign }+\end{array}$ & $\begin{array}{l}\text { Lobulation } \\
\text { sign - }\end{array}$ & $\begin{array}{l}\text { Tumor } \\
\text { vascular } \\
\text { sign+ }\end{array}$ & $\begin{array}{l}\text { Tumor } \\
\text { vascular } \\
\text { sign - }\end{array}$ & $\begin{array}{l}\text { Bronchial cut- } \\
\text { off sign }+\end{array}$ & $\begin{array}{l}\text { Bronchial cut- } \\
\text { off sign - }\end{array}$ \\
\hline PIL & $10^{*}$ & 61 & $3^{*}$ & 68 & $0 *$ & 71 \\
\hline MIA & $5^{\#}$ & 39 & $3^{\#}$ & 41 & $1^{\#}$ & 43 \\
\hline IAC & $146^{*}, \#$ & 133 & $107^{*}, \#$ & 172 & $72^{*}, \#$ & 207 \\
\hline 2-value & 77.416 & & 43.797 & & 33.640 & \\
\hline -value & 0.000 & & 0.000 & & 0.000 &
\end{tabular}

D: Relationship of air bronchogram sign, vacuole sign and cavity sign with pathology

\begin{tabular}{llllllc} 
Pathology & $\begin{array}{l}\text { Air bronchogram } \\
\text { sign }+\end{array}$ & $\begin{array}{l}\text { Air } \\
\text { bronchogram } \\
\text { sign - }\end{array}$ & $\begin{array}{l}\text { Vacuole } \\
\text { sign+ }\end{array}$ & $\begin{array}{l}\text { Vacuole } \\
\text { sign - }\end{array}$ & $\begin{array}{l}\text { Cavity } \\
\text { sign + }\end{array}$ & $\begin{array}{c}\text { Cavity } \\
\text { sign - }\end{array}$ \\
\hline PIL & $10^{*}$ & 61 & 3 & 68 & $0 \%$ & 71 \\
\hline MIA & $7^{\#}$ & 37 & 1 & 43 & 0 \# & 44 \\
\hline IAC & $122^{*, \#}$ & 157 & 23 & 256 & $31^{*, \#}$ & 248 \\
\hline 2-value & 29.920 & & 3.059 & & 13.861 & \\
\hline P-value & 0.000 & & 0.217 & & 0.001 &
\end{tabular}


Note. PIL Pre-invasive lesions, MIA Minimally invasive adenocarcinoma, IAC Invasive adenocarcinoma, CT Computed tomography. ${ } \llbracket$ comparison of PIL and IAC, $P<0.05 \rrbracket \#$ comparison of MIA and IAC $₫ P \otimes 0.05$

\section{Differentiation subtypes in IAC and CT signs}

The relationship between different differentiation subtypes and these signs were expressed in Table 2 . The incidence of the lesions which size $>3 \mathrm{~cm}$ and solid were highest in the subtype of poor differentiation and lowest in high differentiation $(P<0.05)$. While the occurrence rate of mixed ground-glass lesions in poor differentiation subgroup was lower than that of the other two subgroups $(P<0.05)$. The incidence of the lesions which size between 1.5 and $3 \mathrm{~cm}$ and pure ground-glass were significantly higher in high differentiation subgroup than the other two subgroups $(P<0.05)$.The incidence of pleural traction sign, spicule sign, tumor vascular sign, bronchial cut-off sign and cavity sign in poor differentiation subgroup were significantly higher than that in high and moderate differentiation subgroup $(P<0.01)$. The incidence of air bronchogram sign in highly differentiated subgroup was higher than moderately subgroup while the occurrence rate of lobulation sign in highly differentiated subgroup was the lowest among subgroups $(P<0.05)$. The incidence of margin irregularity sign in the poorly differentiated subgroup was higher than in highly differentiated subgroup $(P<0.05)$, but there was no significant difference between the poorly and moderately differentiated subgroup $(P>0.05)$. These subgroups were not significantly associated with the incidence of vacuole sign $(P=0.740)$.

Table 2 Correlation of size and density with different differentiation degrees of IAC

A: Relationship of size and density with different differentiation

\begin{tabular}{|c|c|c|c|c|c|c|}
\hline pathology & size $\leq 1.5 \mathrm{~cm}$ & $\begin{array}{l}\text { Size } \\
1.5 \sim 3 \mathrm{~cm}\end{array}$ & $\begin{array}{l}\text { size } \mathbb{Z} \\
3 \mathrm{~cm}\end{array}$ & $\begin{array}{l}\text { Pure ground- } \\
\text { glass }\end{array}$ & $\begin{array}{l}\text { mixed ground- } \\
\text { glass }\end{array}$ & solid \\
\hline $\mathrm{HD}$ & $7^{\square}$ & $72 \%, \rrbracket$ & $16 *, \otimes$ & $10 \%, \rrbracket$ & $28^{\square}$ & $57^{*, \otimes}$ \\
\hline MD & 1 & $29 *$ & $36 *$ & $1 *$ & $14^{\#}$ & $\begin{array}{l}51^{*} \\
\#\end{array}$ \\
\hline PD & $0^{\square}$ & $36^{\square}$ & $82^{\#, \text { 囚 }}$ & $0^{\square}$ & $7^{\#, \text { 口 }}$ & $111^{\#,}$ \\
\hline $\mathrm{H}$-value & 53.842 & & & 35.613 & & \\
\hline$P$-value & 0.000 & & & 0.000 & & \\
\hline
\end{tabular}

Note. Kruskal-Wall test 
B: Relationship of margin irregularity, plural traction sign and spicule sign with different differentiation

$\begin{array}{lllll}\text { Pathology } & \begin{array}{l}\text { Margin } \\ \text { irregularity }+\end{array} & \begin{array}{l}\text { Margin } \\ \text { irregularity }\end{array} & \begin{array}{l}\text { Plural } \\ \text { traction sign+ }\end{array} & \begin{array}{l}\text { Plural } \\ \text { traction sign- }\end{array}\end{array}$

$\begin{array}{ll}\text { Spicule } & \text { Spicule } \\ \text { sign }+ & \text { sign }\end{array}$

\begin{tabular}{lllllll}
\hline HD & $68^{\square}$ & 27 & $54^{\square}$ & 41 & $43^{\square}$ & 52 \\
\hline MD & 49 & 17 & $37^{\#}$ & 29 & $36^{\#}$ & 30 \\
\hline PD & $101^{\square}$ & 17 & $95^{\#, \square}$ & 23 & $84^{\#, \square}$ & 34 \\
\hline 2-value & 6.818 & & 17.641 & & 15.095 & \\
\hline$P$-value & 0.033 & & 0.000 & & 0.001
\end{tabular}

C: Relationship of lobulation sign, tumor vascular sign and bronchial cut-off sign with different differentiation

\begin{tabular}{lllllll} 
Pathology & $\begin{array}{l}\text { Lobulation } \\
\text { sign }+\end{array}$ & $\begin{array}{l}\text { Lobulation } \\
\text { sign - }\end{array}$ & $\begin{array}{l}\text { Tumor } \\
\text { vascular } \\
\text { sign+ }\end{array}$ & $\begin{array}{l}\text { Tumor } \\
\text { vascular } \\
\text { sign - }\end{array}$ & $\begin{array}{l}\text { Bronchial cut- } \\
\text { off sign + }\end{array}$ & $\begin{array}{l}\text { Bronchial cut- } \\
\text { off sign - }\end{array}$ \\
\hline HD & $35^{*, \square}$ & 60 & $22^{\square}$ & 73 & $11^{\square}$ & 84 \\
\hline MD & $39 *$ & 27 & $20^{\#}$ & 46 & $15^{\#}$ & 51 \\
\hline PD & $72^{\square}$ & 46 & $65^{\#, \square}$ & 53 & $46^{\#, \square}$ & 72 \\
\hline 2-value & 13.914 & & 25.058 & & 21.071 & \\
\hline$P$-value & 0.001 & & 0.000 & & 0.000 & \\
\hline
\end{tabular}


D: Relationship of air bronchogram sign, vacuole sign and cavity sign with different differentiation

\begin{tabular}{llllllc} 
Pathology & $\begin{array}{l}\text { Air bronchogram } \\
\text { sign + }\end{array}$ & $\begin{array}{l}\text { Air } \\
\text { bronchogram } \\
\text { sign - }\end{array}$ & $\begin{array}{l}\text { Vacuole } \\
\text { sign }+\end{array}$ & $\begin{array}{l}\text { Vacuole } \\
\text { sign - }\end{array}$ & $\begin{array}{l}\text { Cavity } \\
\text { sign + }\end{array}$ & $\begin{array}{l}\text { Cavity } \\
\text { sign - }\end{array}$ \\
\hline $\mathrm{HD}$ & $49 *$ & 46 & 8 & 87 & $1^{\square}$ & 95 \\
\hline $\mathrm{MD}$ & $23^{*}$ & 43 & 4 & 62 & $4^{\#}$ & 62 \\
\hline $\mathrm{PD}$ & 50 & 68 & 11 & 107 & $26^{\#, \square}$ & 92 \\
\hline 2-value & 4.583 & & 0.601 & & 25.690 & \\
\hline$P$-value & 0.101 & & 0.740 & & 0.000 &
\end{tabular}

Note. HD High differentiation, MD Moderate differentiation, PD Poor differentiation. ${ }^{*}$, comparison of HD and $\mathrm{MD} \otimes P \otimes 0.05 ;{ }^{\#} \llbracket$ comparison of $\mathrm{MD}$ and $\mathrm{PD} \otimes P \otimes 0.05 \rrbracket \llbracket$ comparison of $\mathrm{HD}$ and $\mathrm{PD} \otimes P \otimes 0.05$

\section{Discussion}

In the process of PIL developing to MIA and IAC, with the increase of tumor cell infiltration and tumor size, the growth rate and resistance of tumor cells in all directions were uneven, the degree of cell differentiation is diverse, and the morphological signs are gradually relatively obvious. According to a study by Oda et al. ${ }^{[15]}$, the occurrence rate of spicule sign in IAC was higher than that in PIL, the difference was statistically significant. Wang et al. ${ }^{[16]}$ reported that the incidence of pleural traction sign, lobulation sign, bronchial cut-off sign, air bronchogram sign and spicule sign in IAC was significantly higher than that in MIA and PIL, while there was no significant difference in cavity sign among the three groups. In our research there was no significant difference in the distribution of vacuole sign in PIL, MIA and IAC, but the incidence of cavity sign in IAC was higher than that in the other two groups, and the difference was statistically significant $(P<0.01)$. The subjects of Wang's paper were all small adenocarcinomas with a certain proportion of ground-glass density lesions, but our study included solid lesions, which may be the reason why the results were inconsistent.

The formation of lobulation sign is mainly related to the different growth rates of lesions in different directions. According to the study of Lee et al. ${ }^{[17]}$, the size, density, lobulation sign, spicule sign and pleural traction sign of the lesion are of great significance in the differential diagnosis between IAC and non-IAC. The findings of our study suggest that the incidence of lobulation sign in IAC group was significantly higher than that in PIL and MIA, which were consistent with the above view. Xiang et al. [18] reported that the signs of air bronchogram and tumor vascular are meaningful for predicting the infiltration degree of lung adenocarcinoma. The occurrence of air bronchogram sign in PIL, MIA and IAC were $14.1 \%, 15.9 \%$ and $43.7 \%$ respectively in our paper, and the incidence rate of tumor vascular sign in the three groups was $4.2 \%, 6.8 \%$ and $38.4 \%$ respectively. The results showed that the incidence of the two 
signs in IAC was meaningfully higher than that in the other two groups, and the difference was statistically momentous $(P<0.05)$. The conclusions of the two studies were consistent. According to many articles in the field, the incidence of these two signs in IAC is higher than that in non-IAC, which is consistent with the consequences of our investigation. It shows that air bronchogram sign and tumor vascular sign have important significance in the differential diagnosis between IAC and non-IAC [19].

The size of the lesion was divided into three grades in our paper, the results display the size of PIL was no significant difference from MIA $(P>0.05)$, the size of IAC lesions was significantly larger than that of PIL and MIA $(P<0.05)$. Recent research has reported that the average axial diameter of IAC is larger than that of non-IAC lesions ${ }^{[20]}$. The above outcome are consistent with the results of our study, which indicated that pure ground-glass density lesions accounted for $80.3 \%, 70.5 \%$ and $3.9 \%$ of PIL, MIA and IAC, no solid lesions were found in 71 cases of PIL, solid lesions accounted for $2.3 \%$ and $68.1 \%$ of MIA and IAC $(P<0.05)$. In the results of Heidinger et al. [21], PIL can be shown pure-ground glass density lesions, and the incidence of pure ground-glass density lesions in MIA was about $40 \%$, while the incidence in IAC was significantly less, which was consistent with the results of our study. Then the study by Eguchi et al. [22] also considered that the degree of infiltration for lung adenocarcinoma was positively correlated with the size and density of the lesion, which was consistent with the results of our study. In pure ground-glass lesions, the distribution of air bronchogram sign, spicule sign, and vascular cluster sign in PIL and MIA was different ${ }^{[23]}$. However, there was no difference in the signs between the two groups in this study. The reason for the different results may be that the lesions collected in this paper included pure ground-glass, mixed ground-glass and solid cases.

The results of previous studies ${ }^{[24-26]}$ could show that the size, density, lobulation, spicule and pleural traction signs of lung adenocarcinoma were different in the incidence of highly and poorly differentiated adenocarcinoma, but there was no statistical difference in the incidence of air bronchogram and tumor vascular signs. In our study, pleural traction sign, spicule sign, tumor vascular sign, bronchial cut-off sign and cavity sign in poorly differentiated subgroup were significantly higher than in the other two subgroups, then there was no difference in vacuole sign among the three subgroups $(P>0.05)$. In this study, the incidence of air bronchogram sign in the highly differentiated subgroup were higher than the moderately subgroup while the lobulation sign was the lowest among subgroups $(P<0.05)$, which was consistent with the Ref. ${ }^{[27]}$. And those differences could be related to the different grouping methods of these studies.

In our study the incidence of lesions of $\leq 1.5 \mathrm{~cm}, 1.5 \sim 3 \mathrm{~cm}$ and $>3 \mathrm{~cm}$ in the highly differentiated subgroup was about $7.4 \%, 75.8 \%$ and $16.8 \%$ respectively, and the lesions of $1.5 \sim 3 \mathrm{~cm}$ were significantly higher than the other two subgroups $(P<0.05)$. Only one case in moderate differentiation subgroup was less than 1.5 $\mathrm{cm}$ in 66 cases, while in the poorly differentiated subgroup, the lesion was more than $3 \mathrm{~cm}$, accounting for $69.5 \%$, which was significantly higher than that in the other two subgroups $(P<0.05)$. The incidence of pure ground-glass lesions in the highly differentiated subgroup was significantly higher than that of the other two subgroups, the most common lesions in the poorly differentiated subgroup were solid 
lesions $(P<0.05)$. The incidence of mixed ground-glass density lesions in the high and moderate differentiation subgroups were higher than that in the poorly differentiated subgroup $(P<0.05)$. The study indicated that with the increase of differentiation degree of invasive adenocarcinoma, the density and size of the lesions gradually increased, which were consistent with the Ref. [28-29].

\section{Conclusion}

It can be concluded that lung adenocarcinoma and its histopathological subtypes as well as degree of differentiation are related to the size, density, pleural traction sign, spicule sign, lobulation sign, tumor vascular sign, bronchial cut-off sign, air bronchogram sign and cavity sign. Based on the imaging characteristics, predicting the histological subtype and differentiation of lung adenocarcinoma can be important for the early diagnosis of partially curable subtypes of lung adenocarcinoma, guiding surgical treatment and evaluating postoperative outcomes. However, this paper is limited to the retrospective nature, some lesions in the blood vascular section and the actual composition of the demarcation is not clear. In addition, all the data are measured manually, which can lead to errors inevitable. Therefore, the accuracy of the conclusion needs to be further verified by overcoming the limitations.

\section{Abbreviations}

SCC: Squamous cell carcinoma; AAH: Atypical adenomatous hyperplasia; AIS: Adenocarcinoma in situ; MIA: Minimally invasive adenocarcinoma; IAC: Invasive adenocarcinoma; PIL: Pre-invasive lesions; CT: Computed tomography; HD: High differentiation; MD: Moderate differentiation; PD Poor differentiation

\section{Declarations}

\section{Acknowledgements}

Not applicable.

\section{Funding}

The project was supported by the science and technology development fund of Nanjing medical University (No. 2016NJMUZD085).

\section{Availability of data and materials}

All datasets generated or analyzed during the current study are involved in this published study. 


\section{Author's contributions}

(I) Conception and design: LL Guo; (II) Administrative support: GM Lu; (III) Provision of study materials or patients: G Bo; (IV) Collection and assembly of data: LZ Duan and WL Shan; (V) Data analysis and interpretation: LL Guo, LZ Duan and WL Shan; (VI) Manuscript writing: All authors; (VII) Final approval of manuscript: All authors.

\#These authors contributed equally to this work.

\section{Ethics approval and consent to participate}

This retrospective study was approved by the local research ethics committee of Huai'an First People's Hospital and was conducted in accordance with the ethical standards of the Declaration of Helsinki.

\section{Consent for publication}

The patient informed consent was waived by the ethical committee because of the retrospective nature of this study, but patient data confidentiality was protected.

\section{Competing interest}

The authors declare that they have no potential conflicts of interest.

\section{author's details}

1Department of Medical Imaging, The Affiliated Huaian No.1 People's Hospital of Nanjing Medical University, Huai'an, 223300, China

2 Department of Medical Imaging, Affiliated Jinling Hospital, Medical School of Nanjing University,

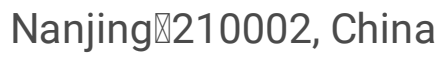

\section{References}

1. Boyle P, Levin B. World cancer report 2008. IARC Press, International Agency for Research on Cancer. 2008.

2. Torre LA, Bray F, Siegel RL, et al. Global cancer statistics, 2012. CA: a cancer journal for clinicians. 2015; 65: 87-108. 
3. Blom JW, Osanto S, Rosendaal FR, et al. The risk of a venous thrombotic event in lung cancer patients: higher risk for adenocarcinoma than squamous cell carcinoma. Journal of Thrombosis \& Haemostasis. 2004; 2: 1760-1765.

4. Coroller T P, Grossmann P, Hou Y, et al. CT-based radiomic signature predicts distant metastasis in lung adenocarcinoma. Radiotherapy and Oncology, 2015, 114(3): 345-350.

5. William D, Travis WD, Elisabeth BMD, et al. International Association for the Study of Lung Cancer/American Thoracic Society/European Respiratory Society international multidisciplinary classification of lung adenocarcinoma. Journal of Thoracic Oncology. 2011; 6: 244-285.

6. Fujimoto $Y$, Togo $S$, Tulafu M, et al. Variation in the expression levels of predictive chemotherapy biomarkers in histological subtypes of lung adenocarcinoma: an immunohistochemical study of tissue samples. International journal of clinical and experimental pathology. 2015; 8: 10523-10533.

7. Shimamura $Y$, Sasaki S, Shimohira M, et al. New technique of percutaneous CT fluoroscopy-guided marking before video-assisted thoracoscopic surgery for small lung lesions: feasibility of using a 25gauge needle without local anaesthesia. The British journal of radiology. 2018; 91: 20170692.

8. Liu S, Zhang LN, He LL, et al. Discussion of Prof. Sun Gui-zhi's Experiences in the Diagnosis and Treatment of Lung Cancer based on the Pathological Subtypes and Pattern/Syndrome Differentiation of Chinese Medicine. World Journal of Integrated Traditional and Western Medicine. 2012.

9. Chen LW, Yang SM, Wang HJ, et al. A competing round-robin prediction model for histologic subtype prediction of lung adenocarcinomas based on thoracic computed tomography. Medical Imaging 2018: Biomedical Applications in Molecular, Structural, and Functional Imaging. International Society for Optics and Photonics; 2018.

10. Cohen J G, Reymond E, Medici M, et al. CT-texture analysis of subsolid nodules for differentiating invasive from in-situ and minimally invasive lung adenocarcinoma subtypes. Diagnostic and interventional imaging. 2018; 99: 291-299.

11. Ko JP, Suh J, Ibidapo 0 , et al. Lung adenocarcinoma: correlation of quantitative CT findings with pathologic findings. Radiology. 2016; 280: 931-939.

12. Eriguchi D, Shimada $Y$, Imai K, et al. Predictive accuracy of lepidic growth subtypes in early-stage adenocarcinoma of the lung by quantitative CT histogram and FDG-PET. Lung Cancer. 2018; 125: 1421.

13. Linning E, Lu L, Li L, et al. Radiomics for Classification of Lung Cancer Histological Subtypes Based on Nonenhanced Computed Tomography. Academic radiology. 2018; 43:300-306.

14. Xiaoli XU, Sui X, Zhong W, et al. Diagnostic value of quantitative dual-source CT dual-energy iodine maps combined with morphological CT features in assessing histological subtypes of lung cancer. Chinese Journal of Radiology. 2018; 52: 823-828.

15. Oda S, Awai K, Liu D, et al. Ground-glass opacities on thin-section helical CT: differentiation between bronchioloalveolar carcinoma and atypical adenomatous hyperplasia. American Journal of Roentgenology. 2008; 190: 1363-1368. 
16. Wang H, Yu W, Pan H Y, et al. Differentiating Preinvasive from Invasive Lung Adenocarcinoma Appearing as Part-Solid Ground-Glass Nodule Using CT Value and Solid-Part Diameter. Iranian Journal of Radiology. 2017; http://doi.org/10.5812/iranjradiol.61846.

17. Lee SM, Park CM, Goo JM, et al. Invasive Pulmonary Adenocarcinomas versus Preinvasive Lesions Appearing as Ground-Glass Nodules: Differentiation by Using CT Features. Radiology. 2013; 268:265273.

18. Xiang W, Xing $Y$, Jiang $S$, et al. Morphological factors differentiating between early lung adenocarcinomas appearing as pure ground-glass nodules measuring $\leq 10 \mathrm{~mm}$ on thin-section computed tomography. Cancer Imaging. 2014; 14:33.

19. Si MJ, Tao XF, Du GY, et al. Thin-section computed tomography-histopathologic comparisons of pulmonary focal interstitial fibrosis, atypical adenomatous hyperplasia, adenocarcinoma in situ, and minimally invasive adenocarcinoma with pure ground-glass opacity. European Journal of Radiology. 2016; 85:1708-1715.

20. Moon Y, Sung SW, Lee KY, et al. Pure ground-glass opacity on chest computed tomography: predictive factors for invasive adenocarcinoma. J Thorac Dis. 2016; 8:1561-1570.

21. Heidinger $\mathrm{BH}$, Anderson $\mathrm{KR}$, Nemec $\mathrm{U}$, et al. Lung adenocarcinoma manifesting as pure ground-glass nodules: Correlating CT size, volume, density, and roundness with histopathologic invasion and size. Journal of Thoracic Oncology. 2017; 12: 1288-1298.

22. Eguchi T, Yoshizawa A, Kawakami S, et al. Tumor size and computed tomography attenuation of pulmonary pure ground-glass nodules are useful for predicting pathological invasiveness. Plos One. 2014; 9:978-979.

23. Gao F, Li M, GeX, et al. Multi-detector spiral CT study of the relationships between pulmonary groundglass nodules and blood vessels. European radiology. 2013; 23: 3271-3277.

24. She $Y$, Zhao L, Dai $C$, et al. Preoperative nomogram for identifying invasive pulmonary adenocarcinoma in patients with pure ground-glass nodule: A multi-institutional study. Oncotarget. 2017; 8: 17229.

25. Yoshino I, Nakanishi R, Kodate M, et al. Pleural retraction and intra-tumoral air-bronchogram as prognostic factors for stage I pulmonary adenocarcinoma following complete resection. International surgery. 2000; 85: 105-112.

26. Meng Y, Liu CL, Cai Q, et al. Contrast analysis of the relationship between the HRCT sign and new pathologic classification in small ground glass nodule-like lung adenocarcinoma. La radiologia medica. 2019; 124: 8-13.

27. Zhang Y, Shen Y, Qiang JW, et al. HRCT features distinguishing pre-invasive from invasive pulmonary adenocarcinomas appearing as ground-glass nodules. Eur Radiol. 2016; 26: 2921-2928.

28. Henschke Cl, Yankelevitz DF, Naidich DP, et al. CT screening for lung cancer: suspiciousness of nodules according to size on baseline scans. Radiology. 2004; 231: 164-168.

29. Cho J, Ko S J, Kim S J, et al. Surgical resection of nodular ground-glass opacities without percutaneous needle aspiration or biopsy. BMC cancer. 2014; 1: 838. 


\section{Figures}
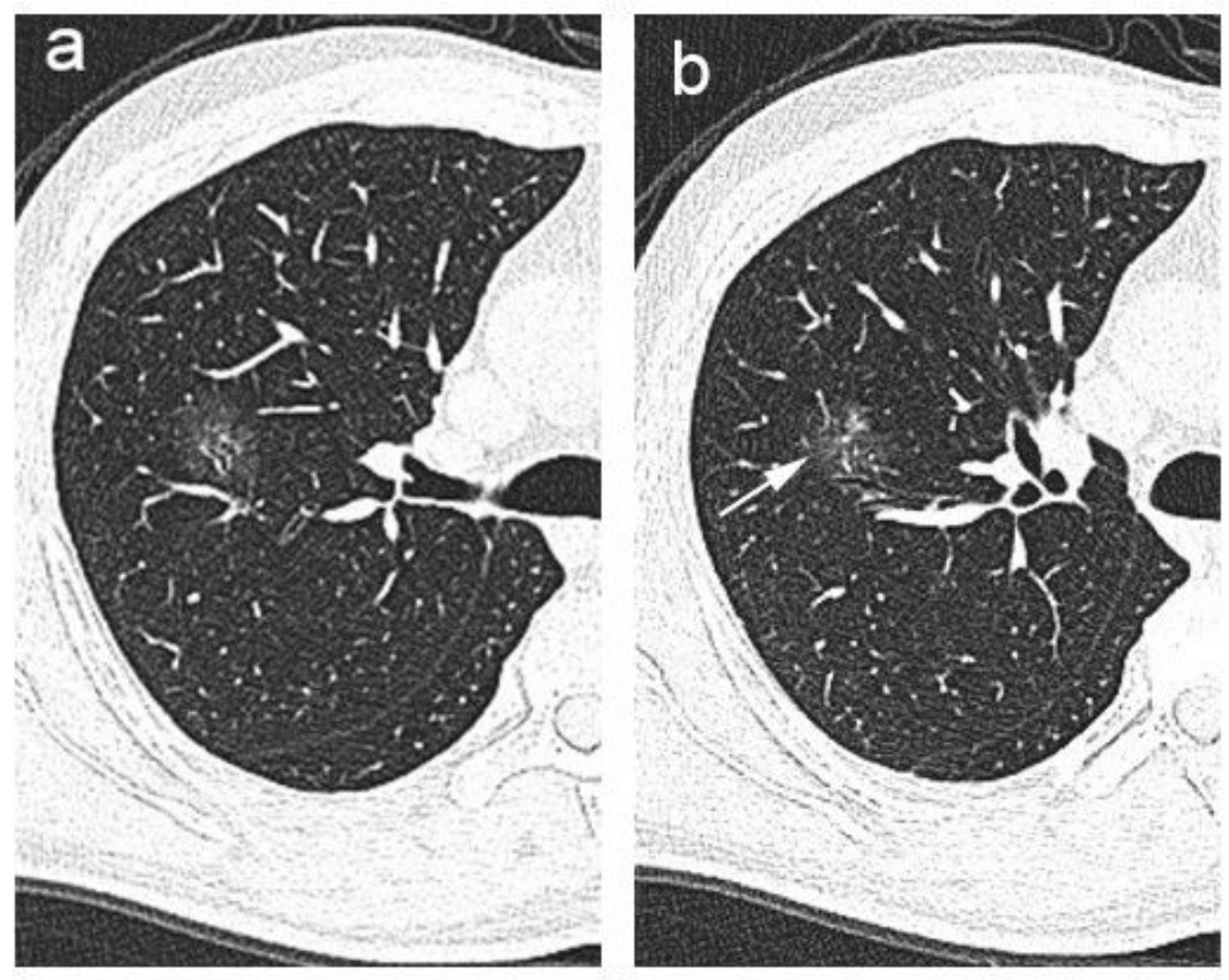

\section{Figure 1}

CT characteristics of the 46-year-old male patient. AAH of segmental alveolar epithelium in the upper lobe of the right lung, with focal area reaching AIS. (a) CT plain scan showed ground glass density of the lesion. The size was $29.6 \times 24.1 \mathrm{~mm}$, the margin was irregular and the bronchial inflatable sign was seen in the lesion. (b) Adjacent blood vessels shift and enter the interior of the lesion, that is, tumor vascular sign (arrow). AAH atypical adenomatous hyperplasia, AIS adenocarcinoma in situ 

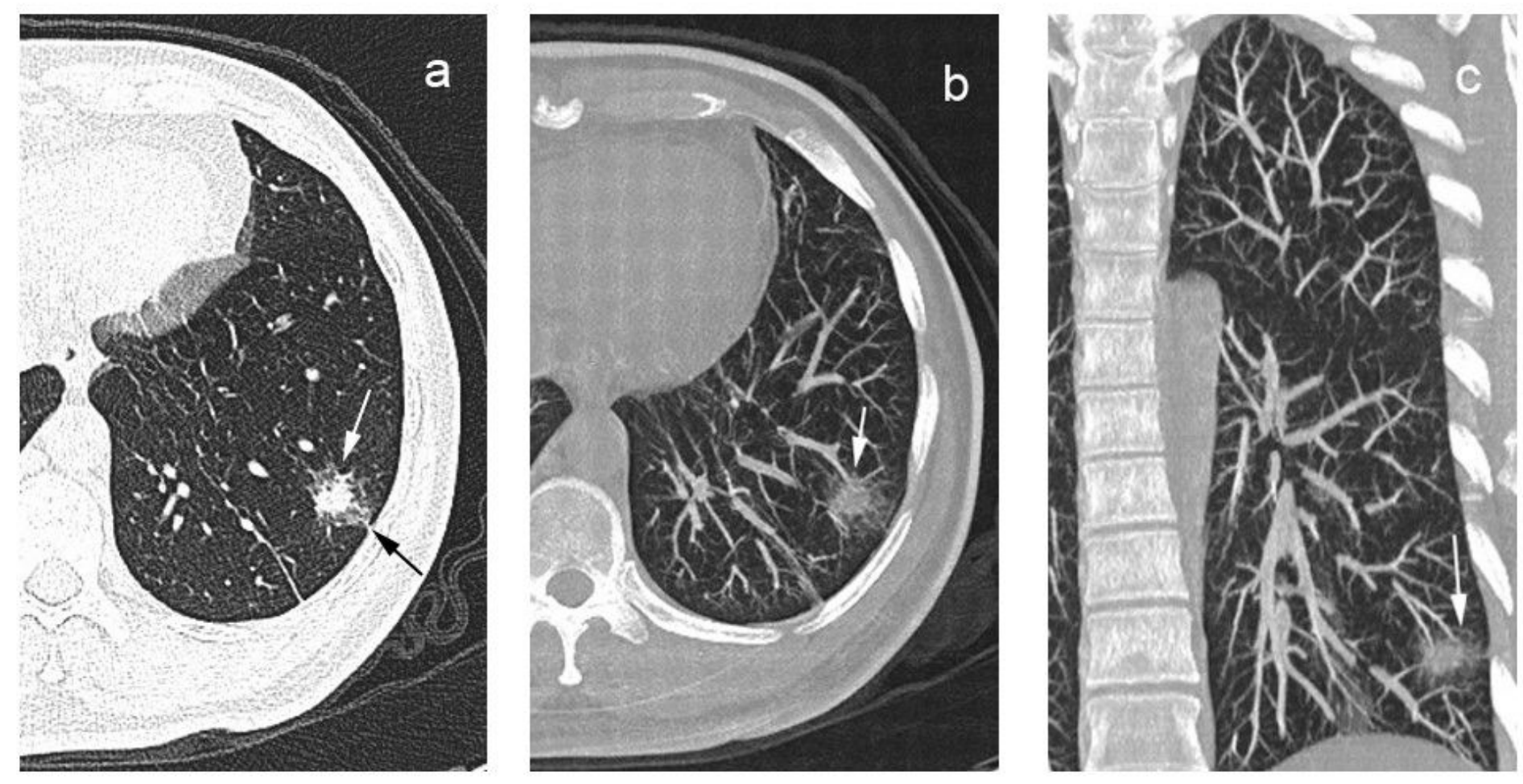

Figure 2

CT characteristics of the 46-year-old female patient, MIA of left lower lobe of lung. (a) CT plain scan showed mixed ground-glass density, which solid density is dominant. The size of the lesion was about $25.9 \times 20.9 \mathrm{~mm}$. the margin was irregular and lobulation sign (white arrow) and adjacent pleural traction (black arrow) could be seen. (b) Tumor vascular sign after MIP recombination. (c) Coronal position of MIP recombination showed that blood vessels entered the lesion. MIA minimally invasive adenocarcinoma, MIP maximum intensity projection 

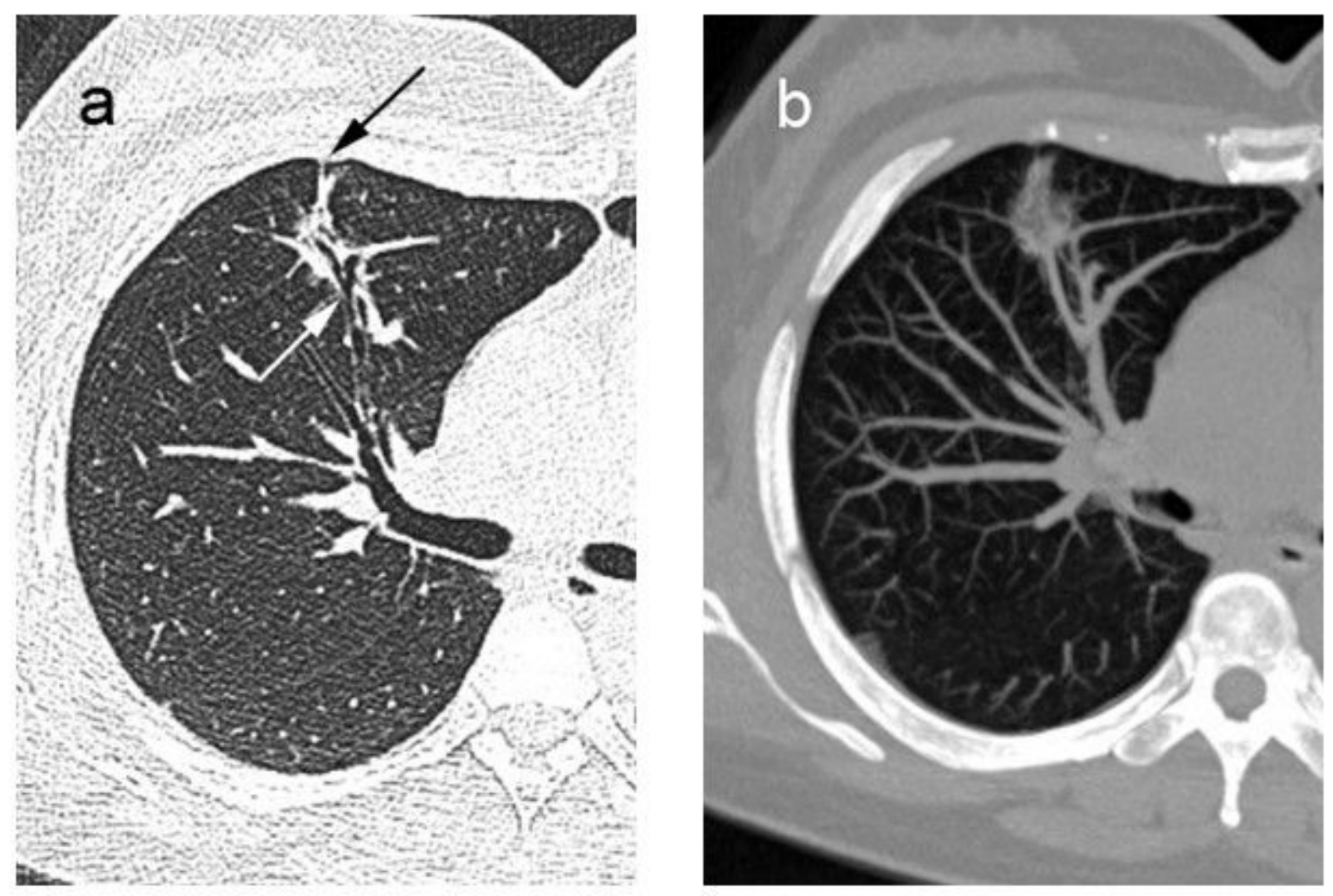

\section{Figure 3}

CT characteristics of the 52-year-old female patient, highly differentiated adenocarcinoma of the anterior segment of the right upper lobe. (a) CT plain scan showed that the lesion was consisted with groundglass density, about $21.6 \times 11.7 \mathrm{~mm}$ in size. The margin was irregular, the air bronchogram inflation sign (white arrow) could be seen in the lesion, and the adjacent pleura was stretched and thickened (black arrow). (b) MIP reconstruction showed multiple adjacent vessels entering the lesion (tumor vascular sign) 

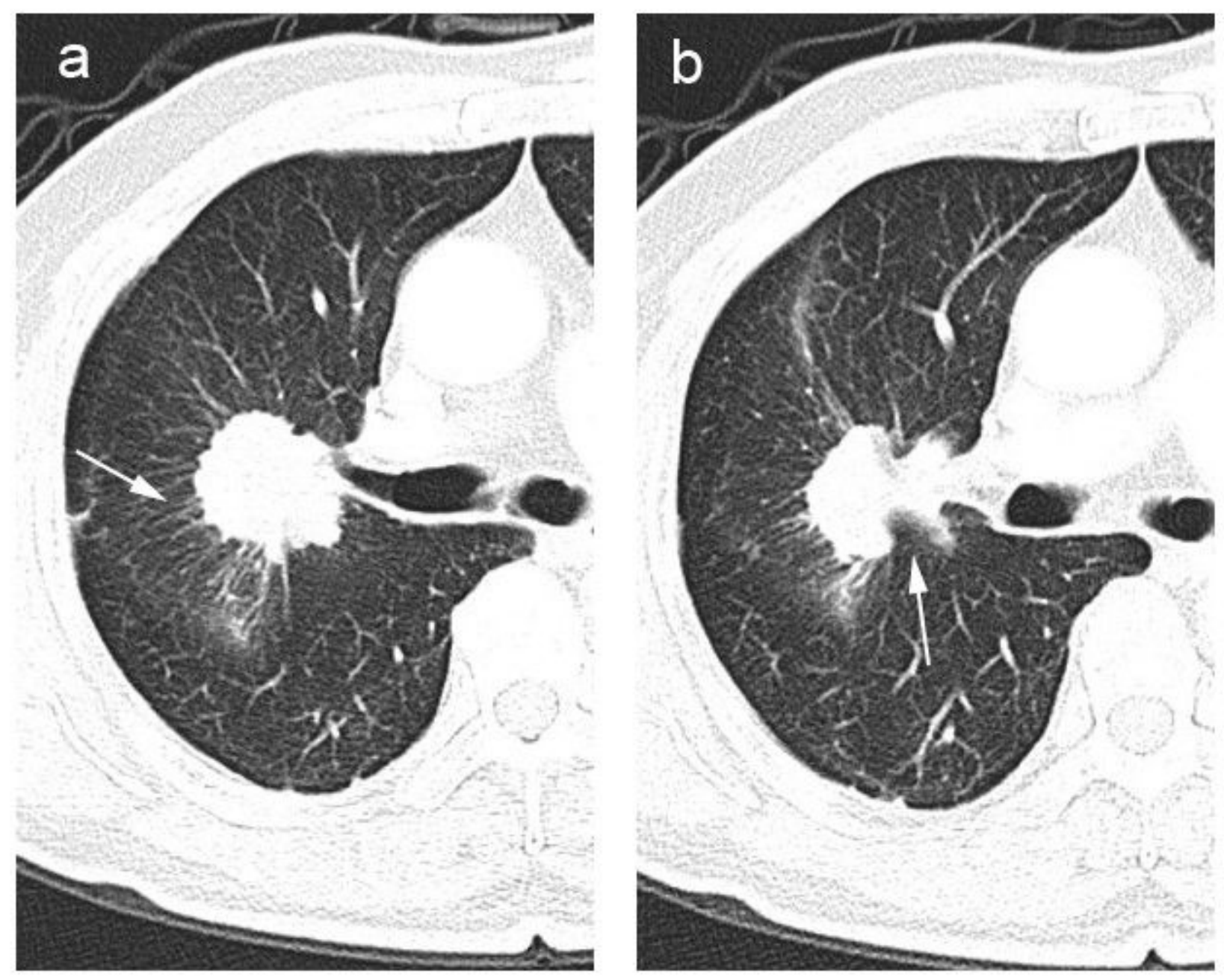

\section{Figure 4}

CT characteristics of the 73-year-old male patient, moderately differentiated adenocarcinoma of the right upper lobe. (a) CT plain scan showed that the lesion was consisted with solid density, about $42.3 \times 37.1$ $\mathrm{mm}$ in size. The margin was irregular, shallow lobulation sign, spicule sign (arrow) and pleural thickening could be seen in the lesion. (b) Deep lobulation can be seen around lesion margin (arrow) 

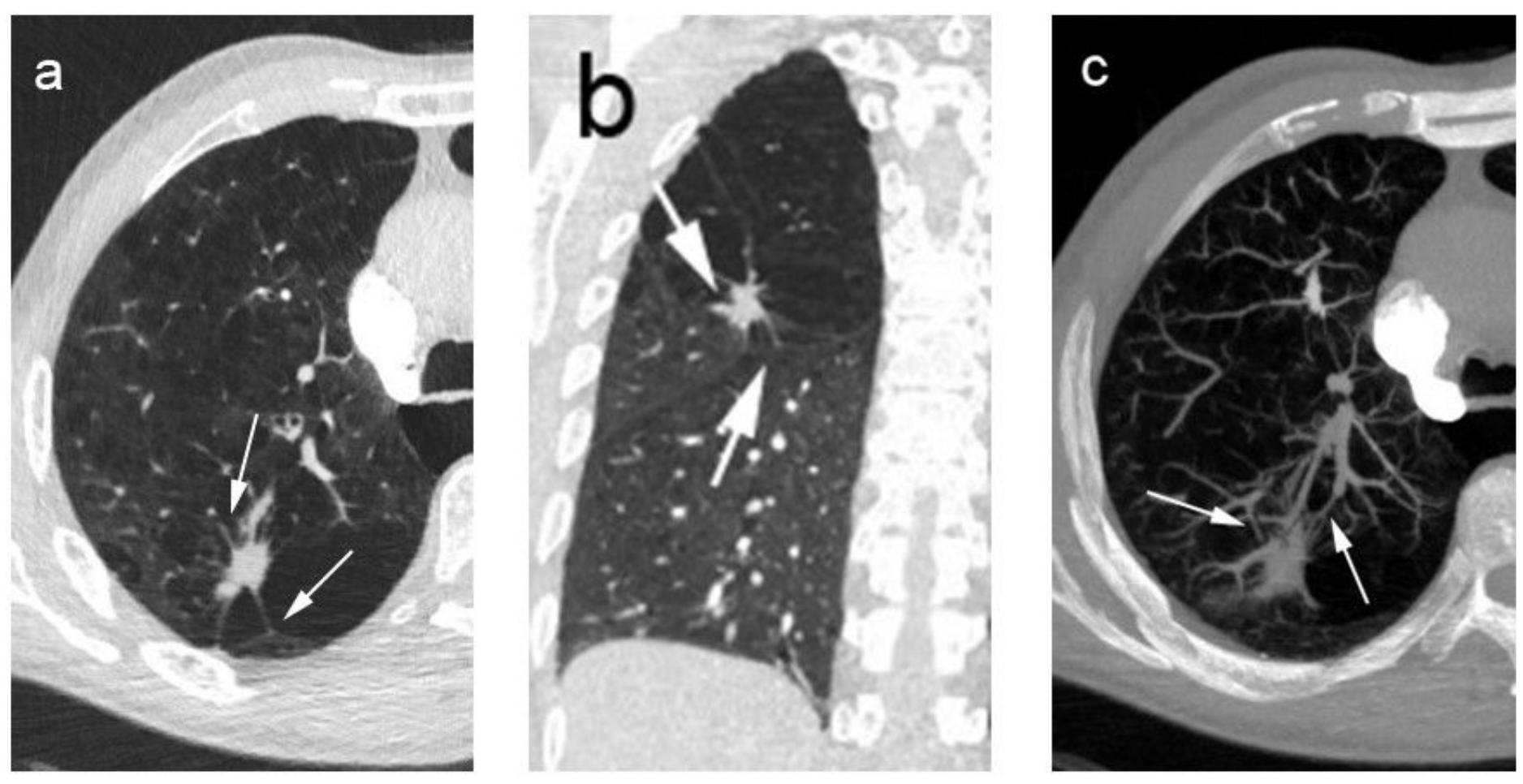

\section{Figure 5}

CT characteristics of the 62-year-old male patient, poorly differentiated adenocarcinoma of the right upper lobe. (a) CT plain scan showed that the lesion was consisted with solid density, about $19.6 \times 10.3$ $\mathrm{mm}$ in size. The signs of spicule, lobulation and pleural traction (arrows) can be seen at the margin of the lesion, and emphysema changes. (b) Sagittal position showed that the interlobar pleura was pulled and displaced, and the lobulation sign can be seen in the margin of the lesion(arrow). (c) Tumor vascular sign (arrow) was shown after MIP recombination(arrow). 